\title{
El pago a las empresas privadas en El Salvador por la prestación de servicios públicos
}

\begin{abstract}
Alvaro Magaña
Por servicio público ha de entenderse toda actividad de la administración pública, o de los particulares o administrados, que tienda a satisfacer necesidades e intereses de carácter general cuya índole o gravitación, en el supuesto de actividades de los particulares o administrados, requieren el control de la autoridad estatal.

La existencia de servicios públicos concedidos a particulares, no implica que la administración pública pierda, en esos casos, su papel y condición de tal, puesto que es a ella a quien le corresponde atenderlos; siendo la concesión sólo un procedimiento para hacerlo, sin que la administración pueda desprenderse de una responsabilidad que le es inherente y no puede rehuir.

El interés público en juego justifica y explica la intervención estatal en la fijación de las tarifas. Como el servicio público satisface necesidades o intereses generales, si se dejare que quienes prestan los servicios actüen con entera libertad en la fijación de tasas o precios, correríase el riesgo de que esos entes o personas expoliasen a los habitantes del país mediante tasas o precios exagerados. La intervención del Estado tiende a impedir esto.
\end{abstract}

Miguel S. Marienhoff. Tratado de derecho administrativo

\section{Resumen}

Este artículo constituye un análisis respecto a la prestación del servicio público. Parte desde su misma definición, sus funciones, el sistema jurídico en que se ampara, el cuestionamiento sobre si continúa siendo servicio público aun cuando sea prestado por particulares, las tarifas en concepto de pago, si pueden ser objeto de lucro, las consecuencias de las políticas neoliberales en este rubro, etc. Con base en este estudio se establece que el Estado presta los servicios públicos de acuerdo con un criterio de rentabilidad, el cual no es sustitutivo de interés general. El Estado debe regular y vigilar los servicios públicos prestados por empresas privadas y aprobar sus tarifas, porque la economía de un país se debe ajustar a las necesidades sociales, por tanto, el Estado debe instrumentar a la economía para beneficio de la generalidad. 
Es importante o, más bien imprescindible, para nuestro estudio recordar que el inciso 4 del Art. 110 de la Constitución de 1983 después de la reforma de 1994 dispone que:

El Estado podrá tomar a su cargo los servicios públicos cuando los intereses sociales así lo exijan prestándolos directamente, por medio de las instituciones oficiales autónomas o de los municipios. También le corresponde regular y vigilar los servicios públicos prestados por empresas privadas y la aprobación de sus tarifas...

Recién concluimos un artículo en el cual comentamos ampliamente la reforma anterior en relación con las curiosas conclusiones de la "Exposición de motivos" del anteproyecto de "Ley de Telecomunicaciones", según las cuales era obligatorio para la asamblea legislativa la aprobación inmediata de dicha ley y, de este modo, hacer la urgente privatización decidida lejos de nuestros país para dar cumplimiento a los esquemas neoliberales que nos han obligado aceptar'.

En el presente trabajo, nuestro interés es particularmente en relación con la parte de la disposición constilucional transcrita, por la cual se establece que también al Estado le corresponde: regulary vigilar los servicios públicos prestados por empresas privadas" y "la aprobación
El Estado podrá tomar a su cargo los servicios públicos cuando los intereses sociales así lo exijan prestándolos directamente, por medio de las instituciones oficiales autónomas o de los municipios.
Estado, la aprobación de las tarifas cuando los servicios son prestados por una empresa pública? y, de igual modo, $¿$ a quién corresponde su aprobación en el caso que ahora estudiamos, o sea, cuando los presta una empresa privada? Sin embargo, para referirnos especialmente al caso particular que nos ocupa, dejamos, el estudio del problema que plantea la primera interrogante para otro estudio que tenemos en preparación y, de igual modo, deseamos advertir que no pretendemos ahondar en los criterios que deben determinar la aprobación de los niveles de las tasas o los precios de los servicios públicos, aún cuando debemos referimos al problema ${ }^{2}$.

El texto del Art. 16 de un anteproyecto de Ley General de Electricidad dispone lo siguiente:

Artículo 16. Régimen de competencia. La prestación de los servicios de electricidad de todo tipo estará bajo el régimen de libre competencia. Los operadores de todos los servicios de electricidad, no tendrán ninguna obligación de prestar servicios, excepto aquellas obligaciones que se deriven de los contratos celebrados con sus clientes. Los precios de todos los servicios de electricidad a los usuarios finales son libres y a discreción de los operadores, salvo aquellos regulados de acuerdo a esta ley"3.

Lo interesante de esta de sus tarifas". Específicamente, estamos interesados en el último aspecto, es decir, en la aprobación de las tarifas por el Estado. Este interés implica aspectos de gran importancia como, ¿a quién corresponde, en el disposición es que establece, por medio de una ley de la república, que los precios de los servicios son libres "y a discreción de los operadores", que es,

1. El artículo titulado "La Exposición de Motivos del anteproyecto de Ley de Telecomunicaciones y la Constitución" fue divulgado en forma equivocada por un matutino y, además, presentada como si hubiera sido una entrevista que nunca se realizó. En todo caso, la mayoría parlamentaria parece haber tomado en serio las conclusiones de esa "Exposición de motivos" cuando aprobó por el Decreto No 807, del 12 de septiembre anterior, la referida ley de telecomunicaciones.

2. Ese trabajo que iniciamos hace algún tiempo lo habiamos titulado "La naturaleza del pago de los servicios de las empresas públicas", donde se examina el problema de la distinción entre tasas y precios públicos. Ahora lo rebautizaremos probablemente como "La naturaleza y aprobación de las tarifas de los servicios públicos", para comprender el caso de los servicios prestados por empresas privadas, que es la cuestión a que nos referimos únicamente en el presente artículo.

3. El documento del cual tomamos el Art. 16 transcrito aparece identificado en su primera página así: "Anteproyecto de Ley General de Electricidad". Proyecto Contrato de Servicios de Consultoría FOMIN-00XX/96. Law and Economics Consulting Group Inc. Emeryville, C.A., Junio, 1996.

4. "Operador" se define en el literal K del Art. 4 del anteproyecto citado como "toda entidad que realiza actividades de generación, distribución o transmisión de electricidad con finalidad de comercialización". 
precisamente, la "confusión" de los autores de la exposición de motivos del anteproyectode ley de telecomunicaciones, pucs interpretan la libertad de empresa y la subsidiaridad del Estado conforme a la Constitución de 1986, cuando el modelo económico de esa Carta Magna fue sustituido desde 1950. No comprenden que la reforma de 1994 al Art. 110 no constituye un cambio significativo de la Constitución económica vigente, porque tal reforma consistió únicamente en convertir en potestativa la prestación por el Estado de los servicios de correos y telecomunicaciones, que antes de 1994 era obligatoria ${ }^{5}$.

Como decíamos en nuestro artículo anterior, el problema de esos "juristas, por supuesto, no es ideológico como ellos dicen, sino que consiste, y llámese como quiera, en identificar libertad de empresa con libertad jurídica total. Parecen creer que después de la reforma de 1994 desapareció todo intervencionismo del Estado y se eliminaron las restricciones a la autonomía empresarial, olvidando lo dispuesto en muchos preceptos de la Constitución de 1983 que no sólo autorizan, sino que obligan al Estado, en determinados casos, a la expropiación (Art. 106), a la prestación de servicios públicos (Art. 1 10, Inc. 4o), a la administración de empresas que prestan servicios esenciales (Art. 112) y a "regular y vigilar los servicios públicos prestados por empresas privadas y la aprobación de sus tarifas" (Art. 1 10, Inc. 4o, aún después de la reforma).

Consideramos innecesario repetir nuestros planteamientos sobre la exposición de motivos de

marras, prefiriendo remitir al lector al artículo en cuestión (ver Eca...) limitándonos ahora a transcribir un párrafo que, en el contexto del presente trabajo, resume nuestros puntos de vista.

El presunto carácter absoluto de la libertad de empresa que rezuma de la $E$ a la $M$ es otra falacia de la larga lista de que está repleto el curioso documento en el quese olvida, pues no se discute, y debe reconocerse que los derechos, como dijimos antes, son por naturaleza limitados o para decirlo con palabras del profesor Luis Prieto Sanchís en sus Estudios sobre derechos fundamentales, Madrid, 1990, cuando nos recuerda que los derechos presentan unos límites inmanentes que derivan de la propia necesidad de preservar no sólo los demás derechos, sino también otros bienes constitucionalmente valiosos ${ }^{6}$.

Los términos en que aparece formulado el Art. 16 del anteproyecto citado muestran un total descono-

5. En relación al contenido y los límites del marco constitucional de la economía, véase Papier, Juan Jorge. "Ley fundamental y orden económico", en Benda, Maihofer, Vogel, Hesse, Heyde, Manual de derecho constitucional, Madrid, 1996, pp. 561 (particularmente pp. 571 y 574). Se trata de una magnífica colección de trabajos de distinguidos iuspublicistas alemanes publicada en su idioma original en 1994. Véase también Sebastián Martín-Retortillo Baquer. Derecho administrativo económico I, Madrid, 1988. Particularmente los capítulos II (p. 70) y III (p. 125.), titulados "Principios económicos de la Constitución de 1978" y "La libertad económica como libertad de empresa", respectivamente.

6. Es preocupante que los principios de esa orientación de la $E$ de $M$ que desconocen y son totalmente ajenos a nuestro ordenamiento constitucional de 1983 y a sus reformas de 1994 sea también verdad revelada, el credo del equipo económico, identicado como el dream team por un matutino que informa sobre un seminario celebrado en Washington, a principios de octubre, que tituló "La venta de un nuevo país" (?). Nos alegra el resonante éxito de ese evento, sólo comparable al de Los del Río con la "Macarena". Nos quedó una duda, sin embargo, no sabfamos si hubo error tipográfico y no es dream team, sino dreamers team. En cuanto al llamado "milagro económico", menos de una semana después de la publicación, tres o cuatro personas que parecen tener los pies en la tierra cuestionaron ese calificativo de ciencia ficción. Al leer y of́r los elogios sobre esas grandes realizaciones y éxitos del neoliberalismo, recordé algo que leí hace tiempo: "la elegía de la zorra que la diga la zorra, el buitre la del buitre y el cobarde la suya". 
cimiento de nuestro ordenamiento constitucional vigente $y$, verdaderamente, nos cuesta creer que pueda encomendarse la preparación de un anteproyecto de ley a quienes desconocen la Constitución salvadoreña. Aprobar una ley, o sea, la función fundamental del legislador ordinario es necesaria y básicamente la Carta Magna y mal pueden formular un proyecto de ordenamiento quienes no conocen nuestro sistema constitucional, en este caso, nuestra Constitución económica. Lo cierto es que no puede esperarse otra cosa cuando es probable que en Emeryville (California) no sepan que tenemos una Constitución y, en verdad, no tienen por qué saberlo. Probablemente sea un caso de no exigibilidad de otra conducta, pero no tenemos dudas de que sí tienen responsabilidad los irresponsables que contratan a estas firmas extranjeras y las dejan sueltas. Por eso es tan veraz aquel dicho mexicano que afirma que la culpa no la tiene el indio, sino el que lo hace compadre.

No tenemos ninguna duda que los términos del Art. 16 del anteproyecto, al ignorar los mandatos del Art. 110 de la constitución, entran en abierta contradicción con el propósito de la reforma reciente de ese precepto que deja a opción del Estado la prestación de cualquier servicio público: "cuando los intereses sociales así lo exijan", y no olvidemos la referencia constitucional a "intereses sociales", pues se trata de un concepto con un contenido bastante indeterminado y, por lo mismo, puede ser objeto de variadas interpretaciones pero, en todo caso, sólo al Estado le corresponde, a través del Organo Legislativo, interpretar en qué caso, o sea, cuándo los intereses sociales exijen aplicar los preceptos constilucionales relativos a la reserva de la prestación de un servicio público por parte del Estado..

Interpretaciones de la Constitución como las de la $E$ de $M$, que estudiamos en nuestro último trabajo, sólo se explican cuando las hace un técnico en Telecomunicaciones o en servicios eléctricos o, en general, personas sin una formación jurídica acorde con nuestro ordenamiento constitucional, porque es obvio que cuando el constituyente establece que el Estado se reserva la prestación de un servicio público es precisamente por eso, porque se trata de un servicio público, que es lo que parecen no tener muy claro los autores de ese proyecto de disposición legal que, afortunadamente, parece que se quedará sólo en anteproyecto y, además, como un buen ejemplo de ignorancia del sistema jurídico salvadoreño ${ }^{7}$.

Consideramos que la explicación fundamental de esas concepciones equivocadas respecto a los alcances de la libre empresa y de las libertades económicas en general, que pretendidamente fundamentan las conclusiones de la despistada $E$ de $M$ y de textos aberrantes de anteproyectos como el caso del Art. 16, muestra un total desconocimiento de que nuestro modelo económico constitucional es diferente de los anteriores a $1950 \mathrm{y}$, lo más importante, que no pudo modificarse con la reforma ilimitada de 1994, la cual expresamente se interpreta de forma errada por ignorancia o mala intención.

Hay una frase reveladora en el texto de la $E$ a la $M$ del anteproyecto de ley de telecomunicaciones que ayuda a explicar planteamientos como lo propuesto en el Art. 16 y otros similares, porque el esquema de globalización los reajustes económicos, la obsesión antiinflacionaria, la campaña para vender el mercadö, etc., son aspectos de ese pensamiento que llaman neoliberal, pero que no es más que el mismo pensamiento liberal del siglo pasado. Loque sí es moderno es la neocorrupción. Dice la referida $E$ de $M$ en su página 6 , refiriéndose a la situación después de la reforma de 1994:

Suprimiendo el régimen de servicio en público entendido en su concepción jurídica y no material debe el legislador secundario en correspondencia con la voluntad del constituyente..

Por favor, no podemos decir, a menos que nos equivoquemos o mintamos, que el constituyente ha suprimido el régimen de servicio público cuando incluso así lo llama en la propia reforma. Lo único que hizo fue convertir la prestación obligatoria de los servicios de correos y telecomunicaciones en facultativas, es decir, el mandato se convirtió en cláusula de habilitación para reservarse la prestación de cualquier servicio público. Pero mantuvo la obligación de regular y vigilar los servicios públicos proporcionados por empresas privadas y la de aprobar sus tarifas, precisamente porque son proporcionadas en un régimen de servicio público en su concepción jurídica, pues si no lo fueran no podrían hacerlo con

7. Pensamos así porque tenemos conocimiento de que se han elaborado dos anteproyectos posteriores al califomiano, citado en la nota 3. El Art. 7 de la recién aprobada ley de telecomunicaciones se refiere a la aprobación de las tarifas y seguramente su constitucional será objeto de estudio. También se aprobó la ley general de electricidad, pero no me refiero a ella, porque no la conozco, pues no me ha llegado el Diario_Oficial, porque hoy hay que mandar a recogerlo. 
tanta amplitud, que es lo que ordenó el constituyente desde 1950.

Es necesaria una aclaración, pues si en este trabajo nos referimos especílicamente al texto del Art. 16 del anteproyecto de ley general de electricidad como ejemplo de nuestra tesis principal $\longrightarrow$ el desconocimicnto de la Constitución-, y además lo relacionamos con la $E$ de $M$ de otro anteproyecto de Ley, es porque simplemente se trata de una misma orientación que considera la libertad de empresa como una libertad absoluta lo cual es contrario al ordenamiento constitucional vigente.

La obnubilación liberal para estar de moda y lleva a afirmar que se suprime el régimen de servicio público mostrando un desconocimiento increíble de los conceptos básicos del derecho administrativo. Digo esto porque no puedo pensar que crean que porque Siemens, Ericsson, AT \& $T$ y otras compañías del mismo tipo den el servicio de telecomunicaciones, ya no era un servicio público. O será que se equivocó el constituyente en 1950, en 1962, en 1983 y el legislador de 1991 y 1994 cuando dijo que correspondía al Estado "regular y vigilar los servicios públicos prestados por empresas privadas y la aprobación de sus tarifas...".

Es verdaderamente lamentable que un concepto de fundamental importancia sea mistificado, desfigurado, mal interpretado y pretendidamente mal usado para descubrir el pensamiento de varios cuerpos constituyentes sucesivos, que usaron la misma fórmula al referirse textualmente a los servicios prestados por empresas privadas. Y la verdad es que porque el Fondo Monetario Internacional, el Banco Interamericano de desarrollo, el Banco Mundial (el $B I D$ ni a eso llega) y la transnacionales ordenan que

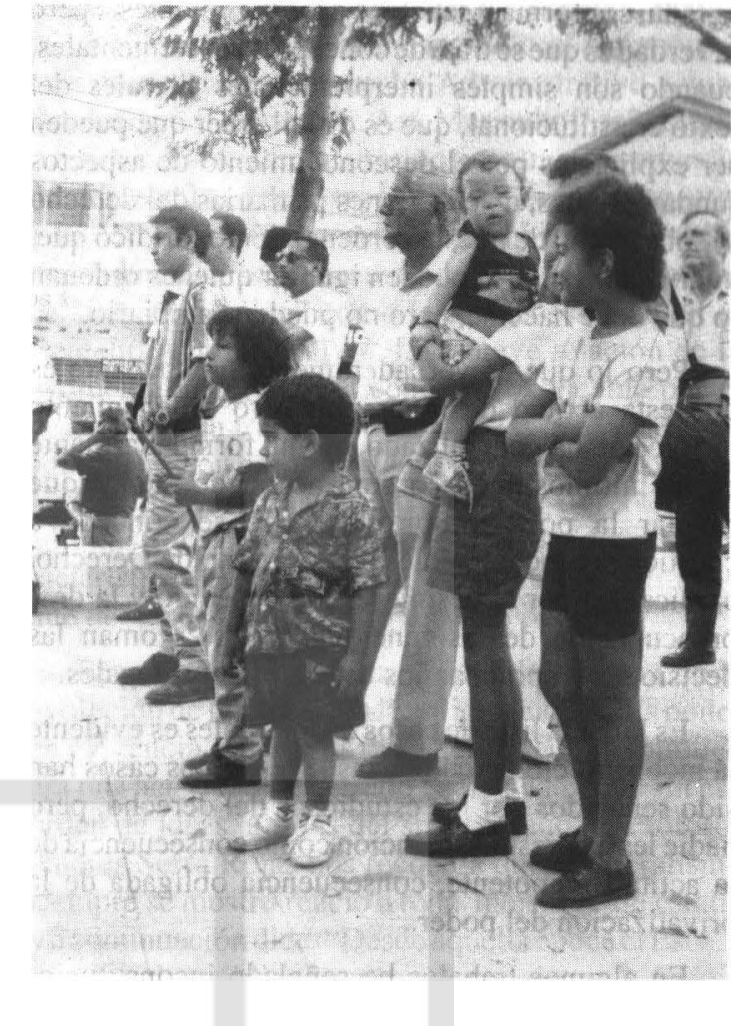

la decisión sobre la prestación de los servicios públicos por la últimas, debe hacerse antes del 30 de diciembre de 1996, y en modo alguno esta orden puede modificar nuestro ordenamiento constitucional. Ya lo dije una vez, el problema es simple: reformar la Constitución para estar en un Estado de derecho como tanto se pregona ${ }^{k}$.

La ignorancia se utiliza para explicar (no excusar) muchas cosas, y hasta pareciera que la explicación

8. En relación al apresuramiento y a la urgencia para llegar a la privatización (en otras áreas del programa neoliberal vamos más que adelantados), son interesantes los señalamientos del presidente de Uruguay, Julio Maria Sanguinetti, respecto a la constitución del Círculo de Montevideo, en una reciente reunión que tuvo lugar en Montevideo y a la que asistieron personalidades como Felipe González, Jordi Pujol, Belisario Betancur, Alain Touraine, Helio Jaguaribe v dos burócratas internacionales: $\mathrm{M}$. Camdessus la E. Iglesias, entre otros. En esa reunión, según palabras del presidente Sanguinetti: “Durante un día y medio, 'a calzón quitado' se habló sobre Los nuevos caminos de América Latina que tal fue el objeto de la convocatoria...". Según la relación del presidente uruguayo ante la realidad de que "si bien la racionalidad macroeconómica había aportado estabilidad, y en muchos casos crecimiento, no había traído como secuela natural una mejoría en la vida de la gente". Y agrega, "Camdessus fue claro: ante esta comprobación, cuidando con imaginar que el péndulo retomará y que ha llegado la hora de desandar parte del camino". Es significativo que los gerifaltes del Banco Mundial ya están a la defensiva. Señala el presidente Sanginetti que "Nadie lo controvirtió, pues se siente que lo hecho, hecho está" y agrega: Aunque discutibles algunas privatizaciones, peor sería plantear la reestatización". No vale la pena comentar. Luego, señala el presidente uruguayo: "Aun quienes nos formamos en el Estado benefactor tenemos claro que el mercado, orientado por la ganancia, asigna mejor los recursos, desplazando la inversión hacia donde tendrá rentabilidad. El tema es otro: esa comprobación, ¿desliga al Estado de todo 
agrada, conforma y satisface a los "ignorantes", pero la verdad es que se trata de conceptos tan elementales, cuando son simples interpretaciones literales del texto constitucional, que es difícil creer que pueden ser explicados por el desconocimiento de aspectos fundamentales, de cuestiones primarias del derecho $y$, sobre todo, de nuestro ordenamiento jurídico que, vuelvo a insistir; lo pueden ignorar quienes ordenan lo que debe hacerse, pero no pueden cambiarlo.

Pero lo que es verdaderamente preocupante es que esta actitud de ignorar nuestro ordenamiento jurídico se ha generalizado en una forma alarmante en los últimos años, lo cual no puede menos que revelar la poca importancia que se concede a cuestiones fundamentales de un Estado de Derecho, explicables por el desinterés, el descuido y la despreocupación de los funcionados que toman las decisiones y aprueban los ordenamientos legales.

Es larga la lista de casos en los cuales es evidente la inconstitucionalidad de las leyes. Estos casos han sido señalados por los estudiosos del derecho, pero nadie les ha prestado atención como consecuencia de la actitud prepotente, consecuencia obligada de la privatización del poder.

En algunos trabajos he señalado inconstitucionalidades en materia tributaria, como es el caso de la modificación de los impuestos de importación por un decreto biministerial, en clara violación del principio de legalidad. De igual modo, la ley del banco central vulnera el precepto constitucional que encomienda la dirección de las finanzas públicas al Organo Ejecutivo en el Ramo correspondiente" (Art. 226). Ley que además estaba viciada desde el punto de vista formal cuando la iniciativa de ley y la refrenda del decreto respectivo las hizo el Ministerio de Planificación debiendo hacerlo el de Economía. De la misma forma, he señalado claras violaciones a principios presupuestarios como el de unidad de caja del Art. 224 y la disposición que establece que la asignación de recursos del Fondo General está autorizada exclusivamente para las instituciones públicas (Art. 225). Para formarse una mejor idea de este cuadro, sólo el Dr Ulises Flores tiene tres o cuatro demandas de inconstitucional y amparo, pendientes de tramitación y resolución desde hace un año, lo cual puede ser en parte explicable por el aumento del recurso de amparo e inconstitucionalidad. Este aumento de demandas obliga a pensar en la conveniencia de establecer, así como están los tiempos, más salas de lo constitucional o un tribunal separado de la Corte Suprema de Justicia, más especializado, sin tantas funciones administrativas y protocolarias, ni que tenga que desempeñarse en el extranjero.

Es curioso que "servicio público" sea una mala expresión en estos días, pues así es como la consideran los que se llaman "neoliberales", y decimos curioso cuando tiene el más puro origen liberal; recordemos que aparece mencionada en la Constitución de Cádiz de 1812 que, por cierto, también decía que "el objeto de gobierno es la felicidad puesto que el fin de toda sociedad política no es otro que el bienestar de los individuos que la componen"; igual que nuestra Constitución Federal de 1824, que dice en su preámbulo que los representantes del pueblo de Centroamérica "cumpliendo con su deseos y en uso de sus soberanos derechos decretamos la siguiente constitución para promover su felicidad". Por eso se ha dicho que, "No es dato para escandalizar a ningún defensor del neoliberalismo la relación trilateral actual entre servicios, tributos y presupuestos, pues se haya técnicamente formulada en términos actuales desde hace casi dos siglos en una Constitución española"y

compromiso social? Así como el mercado tiene esa eficacia en el mundo comercial, ¿ocurre lo mismo con la vivienda o la salud, que son también actividades económicas, pero cuya repercusión social desborda la lógica del lucro?". Concluye el presidente Sanguinetti haciendo el importante señalamiento siguiente: "Hay quienes piensan que no hace falta tanto discurrir. Soy de los convencidos de que en estos tiempos de apresuramiento, por el contrario, más que nunca hay que, cada tanto, detenerse en el camino v volver a reflexionar sobre las grandes cosas" (véase "Los nuevos caminos", El País, Madrid, Edición internacional, 23 de septiembre de 1996, p. 9).

9. Serrano Triana, Adolfo. La utilidad de la noción de servicio público y la crisis del Estado bienestar, p. 20. Las disposiciones de la Constitución de Cádiz de 1812 aparecen con ligeras variantes en los artículos siguientes de la Constitución Federal de Centro América de 1824: Art. 4 (tributos), Art. 69, No 6 (gastos públicos), No 7 (impuestos y otros gastos). Estas disposiciones aparecen de igual modo en la Constitución del Estado del Salvador de 1824: Art. 9. No 3 (tributos), Art 29, No 90 y 10 o (tributos. gastos, presupuesto). Ha llegado hasta nuestros días la "relación trilateral" mencionada en varias disposiciones del Capítulo II del Título VII de la Constitución (Hacienda Pública") y particularmente en el inciso lo. del Art. 231 que establece: "No pueden imponerse contribuciones sino en virtud de una ley y para el servicio público". 
Posteriormente, el pensamiento liberal comienza a considerar el servicio público como pretex to para la intervención administrativa, aun cuando sea un título de intervención justificada. Después, los movimientos sociales de fines del siglo pasado, en Europa, dejaron sentir el principio de igualdad que venía desde la revolución francesa y que se concretaba en las constituciones liberales y las declaraciones de derechos. A continuación sigue la idea del fomento de la riqueza nacional por medio de actividades del Estado. Recordemos que nuestro actual Ministerio de Obras Públicas se llamó antes de Fomento. Del Fomento se pasa históricamente al servicio público que llega en nuestros días a ser una técnica para dar prestaciones sociales, económicas y humanas.

También es oportuno recordar el proceso de construcción jurídica del Derecho Administrativo en el cual los expositores procuraron identificar la idea o ideas unitarias que le dan cohesión para explicar que se trata de una rama del Derecho que goza de autonomía. Entonces, surge como idea básica, que sirve como fundamento y sostén al Derecho Administrativo, la noción de "servicio público". De esta forma se trata de sistematizar todo el Derecho Administrativo sobre la noción de servicio público, llegando a configurar una verdadera escuela que considera que toda la problemática que se plantea en esa área del Derecho puede ser resuelta acudiendo a los principios del servicio público y así, para Duguit, la noción de servicio público contiene y agota toda la estructura del Derecho administrativo. Jeze, que fue quien mejor aplicó las ideas de Duguit al campo específico de lo administrativo, consideraba que el Derecho Administrativo no es más que el conjunto de normas relativas a los servicios públicos.

Después, esa fundamentación del Derecho Administrativo fue objeto de críticas y abandonada, pues si bien es cicrto que la administración pública actúa con el propósito esencial de satisfacer necesidades públicas, no toda actividad desarrollada con ese propósito puede calificarse como servicio público. Hauriou es quien comienza a plantear objeciones de esa naturaleza y sin desconocer su importancia, procura encontrar un principio rector de mayor amplitud frente a la consideración de que administración pública y servicio público no pueden considerarse conceptos equivalentes. Entonces, aparece la que será la tendencia dominante de la doctrina más moderna cuando Mayer señala que es necesario estudiar el acto administrativo para comprender el Derecho Administrativo actual dominado por tal noción. Así, Marienhoff señala que la teoría del acto administrativo tiene una importancia fundamental que debe ser equiparada, en ese aspecto, a la del acto jurídico en el derecho privado. Más recientemente, se ha pretendido proponer la noción de "interés público" como lo que es esencial en el Derecho Administrativo. Esta breve relación de la evolución histórica del concepto explicable por el desarrollo y la transformación de las actividades de administración ha modificado su protagonismo como elemento característico del campo del Derecho administrativo, pero no ha modificado sus características esenciales que permiten configurar lo que debemos entender por servicio público.

El propósito de nuestra resumida relación de la evolución de la expresión "servicio público' es poner en evidencia que en sus orígenes el servicio público era una actividad del Estado exclusivamente. En ese orden de ideas, a fines del siglo pasado, el Profesor Andrés Serra Rojas nos recuerda que el liberalismo siempre se mostró reacio a toda intervención estatal y a continuación dice: "Desde aquella época el Estado como poder público y en uso de su soberanía dividió sus actos, en actos de autoridad y actos de gestión y por medio de los primeros mandaba, en los segundos actuaba como simple particular $\mathrm{Al}$ irse marcando la creciente intervención del Estado, no se concretó a mandar, es decir, dar órdenes, sino que asumió en forma directa y reglamentaba la responsabilidad de proporcionar bienes y ciertos servicios a los administrados; se llamó a esta actividad 'servicio 
público' por su doble carácter de satisfacer una necesidad colectiva y estar atendida_por el propio Estado ". Marienhoff puntualiza (lo que señalamos respecto a Duguil y Jeze) que: "Originariamente hubo quien consideró servicio público toda la actividad del Estado cuyo cumplimiento debe ser asegurado, regulado y controlado por los gobernantes; hubo luego quien restringió dicho concepto, limitándolo a cierta actividad de la Administración pública". Pero lo que es importante para la cuestión que deseamos destacar es que precisa: "Hasta entonces el servicio público sólo concebíase como una actividad desarrollada por órganos estatales" y agrega: "Pero actualmente un sector de la docirina y de la jurisprudencia sostiene que el servicio no sólo puede ser prestado o realizado por organismos estatales, sino también por personas o entes particulares o privados ${ }^{10}$.

Como señala Vedel, igual que otros administrativistas, lo difícil que es precisar la noción de servicio público y lo confuso que ha llegado a ser la noción con la evolución moderna del Derecho Administrativo. "Recordemos como él dice -simplemente algunas ideas generales". Y puntualiza que "El servicio público se puede definir de dos formas, de una manera orgánica o formal, o de una manera material". En la primera forma el servicio público se caracteriza por una cierta organización "se trata de una empresa regida por la Administración". A su vez, la definición material se refiere a la naturaleza de la actividad independientemente de la organización, así se define el servicio público como la actividad que tiende a satisfacer una necesidad general. En el Derecho Administrativo clásico la defínición material y la formal casi coincidían por el estado de la sociedad entonces. Es decir, se podía tomar la expresión en uno u otro sentido concluyendo el Profesor de la Universidad de París: "un servicio públicoera siempre una actividad de interés general desarrollada por la Administración"".
Es decir, históricamente -como seguimos reiterando- el servicio público era actividad estatal $y$, aunque ahora pueden prestarlo entes o personas privadas, no ha dejado de ser un servicio público caracterizado por la presencia de elementos esenciales que no desaparecen aunque ya no sea prestado por un ente público. Estos conceptos son repetidos incansablemente hasta la saciedad por tratadistas respetables, cuyas ideas y conceptos básicos son recogidos por los ordenamientos positivos como sucede en, el caso en estudio, el Art. 110 aún después de 1994 manda que deben regularse y vigilarse "los servicios públicos prestados por empresas privadas" y aprobarse sus tarifas. Las tesis de la E de M tantas veces mencionada y el texto del Art. 16 son simplemente contrarios a la letra y el espíritu de nuestro ordenamiento constitucional.

Pareciera que el problema de esas extrañas interpretaciones se debe a que no se tiene una idea clara de lo que es servicio público. Es lugar común en todas las obras de Derecho Administrativo consignar las dificultades para caracterizar la noción de servicio público; sin embargo, como dice Marienhoff: "El servicio público tiene ciertos caracteres que hacen a su propia 'esencia' y sin las cuales la noción misma de 'servicio público' quedaría desvirtuada". Y después, señala: "La doctrina en general, reconoce los siguientes 'caracteres' del servicio publico: continuidad, regularidad, uniformidad, generalidad". Agrega el distinguido administrativista argentino: "Pero hay otro carácter que es fundamental o esencial... Me refiero a la obligatoriedad de prestar el servicio por parte de quien esté a cargo de éste". Y puntualiza a continuación, "De nada valdría decir que el servicio público debe ser continuo, regular; uniforme y general, si quien debe prestarlo o realizarlo no estuviere 'obligado' a hacerlo". Si recordamos los conceptos del profesor argentino es porque el Art. 16 que transcribimos dice: "Los operadores de todos los

10. Será Rojas, Andrés. Derecho Administrativo, Editorial Pomúa, México, 1988, p. 100; Marienhoff, Miguel S. Tratado de Derecho Administrativo, II p. 19. Gastón Jeze dedica los seis capítulos del Libro Segundo del Tomo II vol. I ("La noción de servicio público"), de sus Principios Generales del Derecho_Administrativo, Editorial Depalma, Buenos Aires, 1949. La definición de Hauriou todavía incluye en su Precis de 1914 como uno de los cinco elementos del servicio público, que lo presta una organización pública (referencia de Serra Rojas op. cit., No 18, p. 104).

11. Vedel, Georges. Derecho Administrativo, Madrid, 1980, p. 688. Serra Rojas en su obra citada se refiere a varios criterios para caracterizar el servicio público y comenta el criterio orgánico diciendo: "que designa la organización pública, es decir al conjunto de órganos y de medios de que provee a la misma, para el cumplimiento de sus cometidos". Y lo considera como: "Criterio insuficiente porque ni todos los servicios de los entes públicos tienen este carácter, ni un servicio público deja de ser público porque sea atendido por una persona privada". $(O p$. cit. p. 103.) 
servicios de electricidad, no tendrán ninguna obligación de prestar servicios...". Y en ninguna parte del anteproyecto se establece la obligación de prestar el servicio ${ }^{12}$.

No es la oportunidad para extendernos sobre estos caracteres, como los califica Marienhoff, pero debemos tener presente que la necesidad de que el servicio público cumpla a cabalidad su función vuelve necesario que esos caracteres tengan una realidad efectiva. Eso explica, justifica y obliga al Estado a regularlos y vigilarlos. Por eso, precisamente, se otorgan las concesiones a los particulares para prestarlos que determinan las condiciones para darlos y obligaciones de quienes los prestan con los usuarios.

No podemos extendernos sobre esos caracteres o elementos de la noción, pues no lo creemos necesario para los alcances de este trabajo. Lo que se debe destacar es que se trata esencialmente de satisfacer necesidades de la generalidad lo cual corresponde al Estado. Eso, precisamente, da al servicio público una connotación que explica porqué el constituyente salvadoreño dispuso regularlo, vigilarlo y aprobar sus tarifas. Por ello, un mal entendido concepto de las libertades económicas en general o de la libertad de empresa en particular, no pueden impedir que el Estado cumpla un mandato constitucional.

La siguiente cuestión a la que deseamos referirnos está concretada en la interrogante siguiente: ¿Cuál es el sistema jurídico aplicable al servicio público?
Marienhoff nos recuerda que desde Jeze, en Francia, se consideró que el servicio se desarrolle de acuerdo con un régimen o procedimiento jurídico especial de Derecho Público. Peroesa tendencia ha evolucionado y probablemente el administrativista argentino citado se acerca a la realidad actual cuando plantca: "A mi criterio no cuadra sostener que el servicio público deba desarrollarse o realizarse de acuerdo al expresado 'régimen o procedimiento jurídico especial de Derecho público', es decir, de acuerdo con un régimen exorbitante del derecho privado, pues hay servicios públicos - los impropios- que no se prestan o realizan en ese régimen o procedimiento especial.

Estimo que basta con que la actividad pertinente quede sujeta o encuadrada en el derecho público, lo que implicará someter dicha actividad a normas de subordinación características del derecho público('subordinación' a la autoridad pública)". Y señala puntualmente a continuación: "Esto vale especialmente para los servicios públicos 'impropios', donde la actividad es desarrollada por entes opersonas "privados '(particulares o administrados)".

Esencialmente de lo que se trata es de aplicar los principios generales del derecho público, pues cualquiera que sean los servicios públicos en el supuesto de los 'impropios' se concreta, dice Marienhoff "en que quien desarrolle la actividad constitutiva del servicio público queda subordinado a la Administración Pública"'?. Por eso en las leyes

12. Marienhoff, Miguel S. Tratado de Derecho Administrativo, cit. Tomo 11, p. 61-62. Serra Rojas en su libro dice que los elementos más importantes del servicio público identificados en su defínición son: ... una actividad técnica, su finalidad de satisfacer una necesidad colectiva realizada por el Estado o por excepción por los particulares y bajo el régimen jurídico especial". Y agrega que hay otros elementos generales como: generalidad, uniformidad o igualdad, continuidad, regularidad, obligatoriedad, persistencia y la gratuidad del servicio. Canasi, otro administrativista argentino, refiriéndose a la definición de servicio público puntualiza: "Su esencia fundamental es la reglamentación unilateral estatal para asegurar la generalidad, uniformidad, regularidad y continuidad del servicio prestado por el Estado (lato sesu) en forma directa, es decir, por administración o en forma indirecta, o sea, por medio de concesionario con quien la administración pública se liga contractualmente". (José Canasi, Derecho Administración, Depalma: Buenos Aires, Vol. II, 1984, p. 20.)

13. Y agrega categóricamente: “A pesar de las sensatas observaciones de quienes sostienen que el régimen jurídico del servicio público tanto puede ser de derecho público como de derecho privado, estimo que el "encuadramiento" de la actividad constitutiva de dicho servicio - sea éste "propio o impropio"- en el ámbito del derecho público es necesario y es conveniente: por esa vía se evitarán los abusos de cualquier orden en que pudiese 
respectivas están determinadas las condiciones de la concesión y las obligaciones de los concesionarios por tratarse de un servicio público que no puede quedar en cuanto a las modalidades y obligaciones de su prestación al criterio de quien lo presta.

Ese gran administrativista mexicano, Don Gabino Fraga, en -cuyo Derecho Administrativo empezamos a aprender muchos, dice: "Mientras la empresa se guíe exclusivamente por el interés de lucro de sus dueños, no existe ni puede existir un servicio público".. Esto nos lleva a la interrogante siguiente que resumimos, igual que lo hacemos con otros aspectos del servicio público, como es el problema del pago de los servicios públicos por el usuario. Este tema lo abordaremos después, pero en el caso de que sean prestados por empresas privadas para dar cumplimiento al mandato constitucional del Art. 110 que deben aprobarse por el Estado ${ }^{14}$.

Antes queremos insistir en que es de la propia naturaleza de todo servicio público el que hay un "interés público" de por medio. Por eso dice Garrido Falla: "Puesto que en estos casos hay un interés público implicado resulta en principio justificada la intervención administrativa por vía de la reglamentación policial": $y$, después agrega, "tal actividad queda sometida a una autorización administrativa previa, la Administración suele aprovechar esta circunstancia para imponer al particular autorizado una serie de cargas y de obligaciones positivas en cuanto a la forma del ejercicio de su actividad..." Este intervencionismo administrativo se explica en la doctrina del servicio público impropio o virtual ${ }^{15}$.

Señalamos antes que en su concepción clásica la noción de servicio público se hacía desde un sentido material, o sea, cuando se trata de una actividad de interés general, o bien desde un sentido orgánico que consideraba su realización por lo poderes públicos. Cuando la noción de la gestión privada de los servicios públicos se acepta en Francia allá por 1920, necesariamente tuvo que prevalecer la noción material del servicio público y a nadie se le puede ocurrir en estos tiempos afirmar, que su prestación estuviera sometida a un régimen de derecho privado's.

A manera de resumen recordemos lo que dice el Profesor Fraga respecto a Duguit cuando consideraba que "el servicio público es un actividad que debe ser ejercitada por el Estado, para Jeze la característica se encuentra en el régimen jurídico aplicable y para Bonnard en el medio, o sea, la organización que permite realizar la propia actividad"17.

Probablemente la lectura del texto de algunas definiciones recientes nos permitirá formarnos una idea de la noción de servicio público generalmente aceptada en la actualidad. Así, para Canassi: "El servicio público puede definirse como la actividad estatal o bajo su control, que tiene por objeto reglamentar tareas de necesidad pública, cuya utilidad efectiva surge de la forma regular y continua de su prestación, conforme a una regla de derecho preestablecida por la autoridad competente de carácter público". Y agrega el mismo profesor argentino,

incurrir quien preste o realice el servicio (verbigracia: exigencia de un precio indebido; negación de vender o de servir; entrega de efectos de inferior calidad con relación a determinado precio; etc.). La aplicación del régimen y de los principios generales del derecho público le brinda a la Administración Pública el medio idóneo para impedir tales excesos". (Op. cit. p 44.)

14. Fraga, Gabino. Derecho Administrativo, Editorial Porrúa, México, p. 536.

15. Garrido Falla, Fernando. Tratado, cit. Vol. II, p. 472 en adelante. En la nota 56 de la página 473 de la obra citada, el profesor español señala —citando a De Laubadere- que hay una corriente jurisprudencial del Consejo de Estado estableciendo que "en ciertas condiciones, las autoridades administrativas, cuando son llamadas a autorizar a los particulares al ejercicio de ciertas actividades, pueden subordinar su autorizacion a obligación de servicio publico", transtomando así, en cierta medida, una actividad privada en un servicio público. Son dos las condiciones que se exigen en tales casos: en primer lugar, es preciso que la actividad en cuestión esté sometida a un régimen de autorización previa; en segundo lugar, se exige que presente un carácter de interés general, es decir, que constituya (según la terminología empleada por el Comisario de Gobierno Chenot) un "servicio público virtual" (Traité élementire, p. 572 y 573).

16. Veáse Weil, Prosper. Derecho Administrativo, Madrid, 1986, p. 100. Marienhoff puntualmente dice: “... el elemento público de la locución servicio público, no se refiere al ente o persona que lo realiza o presta, refiriéndose al destinatario del mismo, es decir a quien dicho servicio va dirigido".

17. Fraga, Gabino. Derecho Administrativo, cit., pp. 22-23. 
"Su esencia fundamental es la reglamentación unilateral estatal para asegurar...". Marienhoff dice: "... por servicio público ha de entenderse toda actividad de la Administración Pública, o de los particulares o administrados, que tienda a satisfacer necesidades o intereses de carácter general cuya índole o gravitación, en el supuesto de actividades de los particulares o administrados, requiera el control de la autoridad estatal". Lo esencial es lo que señala a continuación." "La actividad que despliegue quien preste o realice el servicio tenderá a satisfacer necesidades o intereses de carácter 'general'..."'k.

Estas definiciones recientes y muchas otras similares especifican claramente como requisitos y características esenciales de la noción de servicio público en el contexto del presente trabajo, en primer lugar, que sigue siendo servicio público aún cuando sea prestado por particulares y, segundo, que está sometido a un régimen especial de Derecho Público, por la responsabilidad y obligación del Estado de prestarlo directamente reservándoselo "cuando los intereses sociales así lo exijan" y de regularlos, vigilarlos y aprobar sus tarifas cuando sean prestados por empresas privadas para cumplir el mandato constitucional del Art. 110 inciso 40 .

Si es notorio, en supuestos juristas, el limitado conocimiento de la noción de servicio público, es más evidente que no tienen idea de que los precios pagados por el usuario de un servicio público tienen características particulares precisamente porque se trata de un servicio público aún cuando sean prestados por empresas privadas (servicio público impropio), como será en el futuro con los servicios ahora prestados por ANTEL, GEL, CEPA y quién sabe cuantos casos más de los despojos de las instituciones oficiales autónomas condenadas a desaparecer. Esto es así porque al poco cono- cimiento del Derecho Administrativo de aquellos a quienes encomiendan escribir justificaciones o explicaciones de una ley (eso que llaman exposición de motivos), o a formular textos de proyectos de ley que ahora vemos convertidos en leyes de la República, porque esas personas, como hemos señalado, no tienen idea de lo que es un servicio público, menos pueden entender la naturaleza y el procedimiento para la aprobación del monto que deberán pagar los usuarios por la prestación de un servicio público uti sinquli, es decir, perfectamente individualizado.

Si el régimen del Derecho Público es necesario por el "interés público", cuya satisfacción es esencial en todo servicio público, juntamente con la generalidad, la continuidad, la uniformidad, la regularidad del servicio y la obligación de prestarlo al usuario, probablemente la cuestión más importante es el pago que deben hacer los usuarios, que tiene características especiales que no pueden cumplirse si pudiera dejarse a las fuerzas del mercado, que es precisamente lo que el constituyente salvadoreño quiso evitar conforme al texto del Art. 110, inciso 4o constitucional, aun después de la reforma de 1994.

La importancia del estudio del pago de los servicios públicos por los usuarios es la explicación de que importantes obras de Derecho Administrativo le han dedicado considerable extensión a un problema que es parte integral de la noción de servicio público. En verdad, como precisa Marienhoff cuando se habla de servicios públicos gratuitos, se trata de una gratuidad relativa en el sentido que si bien el servicio no lo paga individualmente cada usuario, lo paga la sociedad en su conjunto a través de los impuestos; en todo caso, el problema solamente puede referirse a los servicios públicos "propios", pues en el caso de los servicios públicos "im-

18. Canasi, José. Derecho Administrativo, cit., pp. 19-20; Marienhoff, Miguel S. Tratado de Derecho Administrativo, cit., Tomo II, p. 55. Del mismo modo, el administrativista mexicano Miguel Acosta Romero al considerar "como elementos esenciales del servicio público: que tiene como finalidad la satisfacción de necesidades de interés general; que puede ser realizada por el Estado o por los particulares; y que debe ser prestado con permanencia y adecuación en un régimen de Derecho público" (Ver Pérez de León E. Enrique. Notas de Derecho constitucional_administrativo, Editorial Porrúa, México, 1989, p. 201. En similares términos también los profesores Gabino Fraga y Andrés Serra Rojas. 
propios", no podrían prestarse sin una retribución del usuario a los concesionarios.

La siguiente interrogante que se plantea el administrativista argentino es que si los servicios públicos pueden ser objeto de lucro "Por principio -dice- y por estar ello de acuerdo con los fines del Estado, éste no. presta los servicios públicos precisamente para 'lucrar' sino ante todo para satisfacer una necesidad o un interés general". Después de aclarar que es impropio hablar de "tarifas" como sinónimo de tasas o precios, porque tarifa es "una lista de los precios o de las tasas"|", precisa que al fijarse las tasas o los precios que los usuarios pagan por los servicios públicos de que individualmente hagan uso, debe respetarse el principio de "proporcionalidad" pues las tarifas deben ser "justas y razonables". Ahora bien, Marienhoff considera que la proporcionalidad consiste en una equivalencia adecuada entre el servicio que se presta y la retribución que por el debe abonarse; así, debe existir proporcionalidad entre la tasa o precio y el costo del servicio que debe hacerse sobre bases reales y verdaderas.

Es innecesario precisar que en los párrafos que anteceden y en los siguientes no pretendemos hacer un estudio completo en relación al problema de la determinación de los precios de los servicios públicos, pues únicamente presentamos una relación muy breve de las características que esos pagos deben tener por tratarse de un servicio público en el que rectamente entendidos esos pagos, son retribución por un servicio de interés general determinante en donde, como regla general, el Estado liene obligación de prestarlo y, lo que es más importante, fijar los pagos por dichos servicios que necesariamente deben ser determinados o aprobados por el Estado como el constituyente con toda propiedad dispuso en el Art. $110^{20}$.

Dice Canasi: "La tarifa no es un precio contractual como equivocadamente sostienen algunos autores; es y debe ser aprobada por la administración". Y cita a Bielsa cuando dice: "Ninguna tarifa es legal ni tiene fuerza ejecutoria si no es aprobada en forma expresa y lundada por el poder administrador". La cuestión fundamental que deseamos descartar y reiterar es que el servicio público tiene características especiales que excluyen la posibilidad de un convenio entre las partes. Marienhoff scñala puntualmente: "El 'interés público' en juego justifica y explica la intervención estatal en la fijación de las tarifas. Como el servicio público satisface 'necesidades' o 'intereses' generales, si se dejare que quienes prestan los servicios actúen con entera libertad en la fijación de tasas o precios, correríase el riesgo de que esos entes o personas expoliasen a los habitantes del país mediante tasas o precios exagerados. La intervención del Estado liende a impedir esto" ${ }^{21}$.

En lo relativo a la intervención del Estado en la fijación de las tarifas de precios, Marienhoff se manifiesta en forma categórica así: "Las 'tarifas', según quedó dicho en el parágrafo anterior, deben ser establecidas o aprobadas por el Estado, cualquiera fuere el tipo del servicio de que se trate. Incluso esto es así tratándose de servicios públicos 'impropios' cuyas tarifas deben ser fijadas por la autoridad". (Op.cit. Tomo II, p. 1 50.) Canasi igualmente corrobora esa posición cuando precisa "... toda tarifa debe ser fijada u homóloga por el concedente, sea directamente por la ley, sea por reglamento delegado". Y agrega que "otro elemento importante de la tarifa es la equidad en su determinación. Con este concepto se expresa el principio de modicidad, justicia y razonabilidad". Y a continuación dice: "Debe agregarse a lo dicho que siendo principio que el servicio público concedido no puede ser más oneroso que si lo prestara directamente el Estado en lo referente al quantum de la tarifa, estamos en un pie de perfecta igualdad con la tasa de servicios cobrados directamente por el Estado". (Op. cit. Vol. II, p. 64.)

19. Señala Marienhoff: "Por eso es que los autores que se expresan con propiedad hablan de precio o tasa del servicio fijado en una tarifa" (op. cit., p. 133). Canasi también se refiere al problema cuando dice que "la expresión "tarifa" que se usa a veces como sinónimo de tasa, o de contribución en general,... es una palabra que más bien denota una forma de graduación, escala o acción de cualquier contribución (en sentido lato). Así podría decirse "tarifa de tasa", "tarifa de impuesto", "tarifa de contribución". La tasa sería una especie de contribución y la tarifa el quantum o tope para el precio o pago del servicio público (op. cit., p. 68).

20. En todo caso, la importancia de la determinación de las tarifas de los precios puede considerarse cuando Marienhoff en su Tratado citado dedica buena parte (el Capítulo VI) del Título Quinto (Servicios Públicos) del tomo II ( $\mathrm{pp}$ 128-156), y Canasi de igual modo estudia las tarifas en forma amplia y detallada en las secciones 6 y 7 del Capítulo XIII sobre los servicios públicos del volumen II de su Derecho Administrativo cit. (pp. 34-75).

21. Marienhoff, op. cit., p. 149; Canasi, op. cit., pp. 54 y 55. 
El otro aspecto importante de los servicios públicos que mencionamos antes, sobre el que deseamos insistir con las palabras siguientes de Marienhoff: "La generalidad de la doctrina, cuyas conclusiones comparto, considera que en la especie el administrado tiene un derecho subjetivo_a que el servicio le sea prestado". (Marienhoff, Op.cit. Tomo II, p. 161.)

Si hemos consignado la generalizada opinión de respetados tratadistas es únicamente para sustentar doctrinariamente nuestra posición contraria a los documentos a que nos referimos en este trabajo. Pero, en todo caso, nuestro Art. 110 constitucional recogió esos principios y si hemos querido señalar cuales deben ser las características de lo que se pague por los servicios públicos cuando lo presten empresas privadas, es para que tales principios orienten las actuaciones de las autoridades que aprueban el monto de esos pagos, de manera que esa aprobación no signifique una simple aceptación de lo que las empresas transnacionales quieran cobrar.

En las páginas anteriores hemos tratado de reseñar de manera breve lo que es el concepto de servicio público,lo cual parecen ignorar los que enamorados del liberalismo toman las grandes decisiones (o mas bien las obedecen) de nuestra política económica. No es costumbre nuestra incursionar en áreas ajenas a lo que ha sido materia de nuestro estudio y experiencia, pero para justificar las privatizaciones se ha insistido exageradamente en la ineficiencia estatal, que si ha existido, puede afirmarse que mas bien es producto de la corrupción, que ahora y en el futuro tendrá modalidades modernas que vamos a identificar como la neocorrupción del liberalismo de siempre, que ha logrado su más grande triunfo al privatizar el poder.

Pero no podemos olvidar e ignorar que servicios esenciales como la electricidad, las telecomunicaciones, el agua, etc. fueron iniciados y desarrollados por el Estado, y no han sido tan malos ni tan caros hasta muy recientemente. Un apreciable jurista trató de que recordáramos esos esfuerzos del estado y en un artículo todavía inédito decía refiriéndose al año 1961: "En cuanto a teléfonos, asimismo ya para el año citado se había cambiado radicalmente por el de discado directo de teléfono a teléfono y aumentado el numero de teléfonos instalados. Para 1980 las estaciones terrenas y la comunicación telefónica con el resto del mundo nos colocaban en una posición líder en relación, por ejemplo, con el resto de Centroamérica. Y hoy, con el sistema de teclado, los cables de fibra óptica, el fax y la telefonía celular, el gobierno ha continuado la modernización de las telecomunicaciones en forma sustancial"22.

22. El Dr. Armando Peña Quezada tituló su artículo "Los puntos en su lugar. La verdad sobre la modernización de las telecomunicaciones" en el que hace también este señalamiento: "Se dice que para el año 2005 habrá una demanda de más de un millón de líneas telefónicas y esto es una descomunal mentira, que se prueba fácilmente así: hoy tenemos seis millones de habitantes de los cuales un setenta por ciento son pobres o miserables: por consiguiente, ese setenta por ciento que equivale a cuatro millones doscientos mil, no pueden tener teléfono porque no tienen con que pagarlo; el resto que es un millón ochocientos mil debe reducirse a grupos familiares que serían cuatrocientos cincuenta mil grupos cuya demanda de teléfonos sería efectiva y que para el año 2005 puede llegar a quinientos mil teléfonos. Pues bien, si ya hay instalados trescientos mil teléfonos, las necesidades a cubrir para el año 2005 serían únicamente unos doscientos mil teléfonos". En otro artículo titulado: "Los puntos en su lugar. La verdad sobre la modernización de la CEL" dice: "Hoy no se quiere recordar esa realidad ni la magnitud y calidad de su ejecución. En la década de los cincuenta y sesenta se construyó la represa 5 de noviembre y, posteriormente, se construyeron las represas el Guajoyo, Cerrón Grande y la 15 de Septiembre; al mismo tiempo, se construyeron las líneas de transmisión, las sub-estaciones $v$ las líneas de conexión. Estas frías palabras tal vez no dan una idea real de la verdadera magnitud de toda esa labor que se hizo con personal salvadoreño muy calificado liderado durante mucho tiempo por el verdadero señor, capaz y honesto, que fue Victor de Sola. Además, con encomiable previsión la CEL exploró el aprovechamiento de nuestra energía geotérmica y lo hizo realidad: esto ha sido admirado y elogiado en el ámbito internacional". Un comentario final: quizás nunca se leerán esos trabajos. porque fueron enviados a dos periódicos a mediados del pasado mes de septiembre. Porque no se interesan los inversionistas privados en el "metro" de San Salvador. ¿O será mejor que la Alcaldía se endeude y entonces privatizarlo?, es sólo curiosidad. 
Concluye el Dr. Peña Quezada: "De las realidades expuestas se deduce: (a) que el EstadoGobierno se ha visto obligado a hacerse cargo de las telecomunicaciones por incapacidad o defecto de la iniciativa privada; (b) que el Estado-Gobierno ha modernizado progresiva y satisfactoriamente las telecomunicaciones; (c) no existe ningún impedimento para que el Estado-Gobierno continúe su labor de modernización de las telecomunicaciones y puedan estar completamente actualizadas en el año 2005; y respecto a CEL dice: “...si la CEL se ha modernizado progresivamente, cumpliendo a cabalidad con una enorme proyección financiera y tecnológica de la electrificación de nuestro pais, que ha sido fundamental para nuestro desarrollo, y si nada impide que se pueda recuperar la tradición de capacidad y honestidad en su administración establecida por Víctor de Sola, como parece que lo esta haciendo Billy Sol Bang, ipor qué o para qué privatizarla?"

No es la oportunidad para extendernos sobre las presumibles bondades atribuidas interesadamente a los procesos de privatización y, no obstante, experiencias desafortunadas en muchas partes, se continúa con ese empeño del que terminaremos arrepintiéndonos. La experiencia de la privatización en México es una prueba de cómo no debe hacerse y que por cierto se parece bastante a la nuestra. Basta recordar que en 1995, la empresa privada de telecomunicaciones tuvo los rendimientos más elevados de todas las actividades económicas en ese país, y los precios de los servicios son ahora tres o cuatro veces lo que fueron en el pasado. Allí están también las experiencias de México y la reciente de Argentina que ha provocado uno de los paros laborales de protesta más impresionante, cuando el despido sin indemnización es pieza esencial del neoliberalismo.

En la revista Siempre de México (No 2235, 1996, p. 46) aparece el interesante señalamiento siguiente: "Los neoempresarios del neoliberalismo ostentan estilos de vida superiores incluso el del american way of life. Ello es posible porque las condiciones generales de vida en nuestros países están bien lejos de las que predominan en el primer mundo. El ingreso promedio por habitante en Estados Unidos ronda los 25 mil dólares anuales, mientras que en Chile es de 8 mil 400; en Argentina de 8 mil 200; en Perú, 3 mil 200 y en El Salvador, 2 mil 350 dólares (para mencionar cuatro estrellas del neoliberalismo latinoamericano). Tener condiciones de vida similares a los de las élites de países del primer mundo cuando se vive en países con ingresos entre 50 y 80 por ciento debajo de aquellos, sólo es posible con una tremenda desigualdad social: mientras que el 10 por ciento más rico de los hogares de Estados Unidos capta 25 por ciento del ingreso nacional, en Perú, el 10 por ciento más rico capta 36 por ciento; en El Salvador casi 40 por ciento, en Chile casi 46 por ciento y en Argentina, 37 por ciento. Estas enormes disparidades refuerzan el sentido de impunidad de los de arriba y deterioran la posibilidad de desarrollo de un sentido de pertenencia compartida a una comunidad nacional".

En el presente trabajo, igual que en otros, hemos hecho repetidos señalamientos sobre las serias consecuencias de las políticas neoliberales que obligadamente seguimos y que ocurrirán al agravarse los problemas sociales e, incluso, ya estamos observando en otros países, como los casos de Argentina y México, por ejemplo. Hemos insistido también que desde el punto de vista de los ciudadanos de Estados presumiblemente soberanos e independientes resulta difícil entender que decisiones trascendentales para el futuro de nuestro país se adopten ignorando nuestros problemas porque con toda razón quienes las hacen están pensando en sus propios intereses, que no son los nuestros. En el caso concreto de Argentina son impactantes las recientes declaraciones ( $22 \mathrm{dc}$ oclubre de 1996) del expresidente Raúl Alfonsín, que refiriéndose a la venta de las empresas públicas dijo que después de "vender las joyas de la abuela (por las privatizaciones)" el oficialismo "pretende ahora vender a la propia abuela". Y yo agrego, las joyas de la abuela se vendieron en veinticinco mil millones de dólares y, adivine el lector, se gastaron y el endeudamiento además aumentó!??

23. Esas declaraciones del expresidente argentino: aparecen en una información que fácilmente pasa desapercibida pues se titula: "E.U.A. quiere prueba de amor por semana", publicada en La Prensa_Gráfica de 28 de octubre de 1996, pág. 55 A. También dijo: "No debemos echarle la culpa de todo lo que sale mal a la corrupción, ya que en realidad, todo es resultado de la inmoralidad estructural del modelo". También dice la noticia avalada por $A F P$, que el expresidente Alfonsín aseguró que Argentina es "una colonia del imperialismo", que las 
Por otra parte, funcionarios de alto nivel de organismos internacionales plantean cuestiones que llevan a la reflexión, cuando esos organismos obligan a los programas de ajuste que conllevan todas esas medidas extremas del llamado neoliberalismo, lo cual deberían observar nuestros obedientes funcionarios respecto a quienes una vez dijimos que habían salado más papistas que el Papa o, mas bien, más fondistas que el Fondo. En relación con las declaraciones de esos funcionarios internacionales, para citar un caso, se ha dicho: "... de acuerdo al más orlodoxo pensamiento económico liberal, se debe reconocer que el mercado, siendo el mejor sistema para optimizar la asignación de los recursos económicos, por sí solo no produce competencia, que es la esencia de su eficacia, ni equidad que es el fundamento de su legitimidad. Hay aquí un papel insustituible del Estado"24.

También es preocupante la situación de algunos países que explica porqué el Presidente Cardoso del Brasil dijera en una ocasión que en América Latina está pendiente "volver público al Estado".

La breve relación anterior del concepto de servicio público tiene como único propósito tratar

de caracterizarlo, identificar aquellos aspectos que necesariamente forman parte de él y que no pueden ignorarse, pues al hacerlo estaríamos desnaturalizándolo. Aparece, entonces, que nuestros constituyentes sucesivos cuando emplearon la expresión en el Art. 110 actual y en sus antecedentes, estaban conscientes de las características básicas que debe tener para cumplir sus objetivos. Ello explica y justifica además, que el Estado debe regular y vigilar los servicios públicos prestados por empresas privadas y aprobar 'sus tarifas que son obligaciones mantenidas por casi medio siglo, las cuales no se

decisiones "fundamentales" del gobierno "se toman en los Estados Unidos" y que las "relaciones carnales piden una prueba de amor por semana". No hay más que agregar. Para una reciente relación de la experiencia mexicana véase México: en la frontera del caos, Vergara Editores, México, abril de 1996, cuyo autor es el ganador del Pulizzer y del premio Ortega y Gasset, Andrés Oppenheimer y, respecto a los problemas para sacar adelante su modelo económico, son interesantes los recientes señalamientos del exsccretario de Hacienda y Crédito Público, David Ibarra Muñoz, en su reciente libro "¿Transición o crisis? Las contradicciones de la política económica y el bienestar social, Proceso, No. 1042, octubre, 1996. Por otra parte, es significativo que las consecuencias y efectos de las políticas liberales comienzan a preocupar a la generalidad y así, son más que interesantes los conceptos de Carlos Espinoza de los Monteros, presidente del Círculo de Empresarios Español cn un artículo titulado: "Salvemos el Estado de bienestar", $A B C$, Madrid, octubre, 1996, p. 43.

24. "América Latina recuperar la esperanza" por Edmundo Jarquín, quien es Jefe de la Unidad del Estado y Sociedad Civil del Banco Interamericano de Desarrollo (BID) en El País, octubre, 1996, p. 14. En ese artículo señala el autor que "debe fortalecerse la capacidad fiscal del Estado para que pueda cumplir sus responsabilidades básicas en materia de educación y salud que constituyen el piso de la igualdad de oportunidades y del éxito económico de los países" pero a continuación agrega: "Hasta ahora sin embargo el apremio fiscal de los equilibrios macroeconómicos ha conducido en general a una debilidad de las capacidades del Estado para cumplir con esa responsabilidad básica, y la estructura fiscal, en general, no se compadece con los objetivos de la cohesión social". El presidente Sanguinetti en el artículo citado en la nota 8 señala los errores de los populismos y también que los "neoliberalismos ortodoxos propusieron el Estado mínimo, el desmantelamiento de su intervención, la privatización generalizada, la confianza en que las solas fuerzas del mercado generarían la prosperidad luego de alcanzar cl crecimiento". Después concluye: "Lo que está claro es que América Latina tiene presente su catálogo de errores pero aún no ha encontrado su manual de ruta para el futuro que se vino. El futuro ya no es lo que era" agrega, recordando a Paul Valery en la reunión del Círculo de Montevideo. 
hubieran establecido en nuestro ordenamiento constitucional si no hubieran querido ser consecuentes sus autores con el concepto de servicio público de general aceptación en la doctrina y los ordenamientos jurídicos de la gran mayoría de paises.

Por eso, pretender a estas alturas que el cumplimiento de elementos esenciales de un servicio público no es responsabilidad del Estado significaría retroceder un siglo en el desarrollo de una noción, lo cual significaría volver a sus inicios. Pero no debe sorprendernos el hecho de que parece haberse detenido el tiempo en la noción de servicio público, pues tal como lo consideran los modernos reformistas es totalmente congruente con la orientación de las Constituciones liberales del siglo pasado. Por eso hemos insistido en distintas oportunidades en que el problema parece radicar en no haberse dado cuenta que desde 1950 cambiamos nuestro modelo económico de los ordenamientos constitucionales anteriores a ese año. Pero antes de terminar, volvamos al servicio público, porque es necesario dejar claro, de una vez por todas, que por opinión unánime si la evolución llevó a que un servicio público fuera prestado por particulares, eso no cambia su propia naturaleza de servicio público.

Leímos recientemente en una obra del Profesor Escola un párrafo, que seguramente desconocen quienes pretenden interpretar la Constitución como se hacía hace cien años, aun cuando nos resulta más difícil explicarnos la concepción del servicio público a estas alturas, revelador de haberse quedado detenidos en el tiempo y no han podido superar aquellas etapas cuando a finales del siglo pasado, la expresión comienza a identificarse con ciertas actividades como propias y constitutivas de algo concerniente a la colectividad y lo que además no pueden olvidar es que hace un siglo el título de servicio público se convierte para los liberales, en un pretexto de intervención, aun cuando fuera una intervención justificada para dar respuestas efectivas a las necesidades de distintos grupos sociales. Después de 1950, entre nosotros, cuando nuestra Constitución de ese año sustituye el modelo liberal del siglo pasado, no tiene sentido - al menos constitucionalmente - sostener puntos de vista extraños y antagónicos a nuestro ordenamiento jurídico ${ }^{25}$.

Para retomar nuestra exposición, recordemos el párrafo relativo a lo que decía el Profesor argentino citado, reiterando lo que ya antes señalamos:

"La existencia de servicios públicos concedidos a particulares, no implica que la administración pública pierda, en esos casos, su papel y condición de tal, puesto que es a ella a quien le corresponde atenderlos, siendo la concesión sólo un procedimiento para hacerlo, sin que la administración pueda desprenderse de una responsabilidad que le es inherente y no puede rehuir" $"$.

El constituyente salvadoreño ha tenido una idea clara del concepto de servicio público en la doctrina y, lo que es más importante, lo que él quiere que sea en nuestro ordenamiento constitucional. Por eso manda en el Art. 110 inciso 4o, que el Estado: (1) puede reservarse la prestación de cualquier servicio público; (2) debe regular y vigilar aquellos prestados por empresas privadas y, (3) debe aprobar

25. Serrano Triana, Adolfo. La utilidad de la noción de servicio público y la crisis del Estado bienestar, Instituto de Estudios Laborales y de la Seguridad Social, Madrid, 1983, particularmente la sección 3. "La vinculación del liberalismo con el servicio público", pp. 23-25.

26. Escola Héctor, Jorge. El interés público como fundamento del Derecho Administrativo, Ediotorial Depalma, Buenos Aires, 1989, pp. 127-128. Que es la misma idea concretada por otro administrativista cuando dice: "El Estado al otorgar una concesión de servicio público, como de transporte colectivo de alumbrado público, de agua potable, etc. y fijar las condiciones en que el concesionario prestará el servicio, no se despoja de sus facultades soberanas ni del deber que tiene de atender las necesidades públicas en las condiciones que esas necesidades lo exijan. Si aquellas requieren mejoras en el servicio, el interés particular del concesionario no puede anteponerse al interés de la sociedad entera: corresponderá dar a éste las compensaciones adecuadas, pero nunca podrá prevalecer una disposición contractual que impida, al Estado cumplir con sus fines públicos, los que, por su esencia, son irrenunciables". (Varas C., Guillermo. Derecho Administrativo, Editorial Nacimiento, Santiago, Chile, 1948, pp. 319-320). De igual modo, un profesor español señala: "Verdaderamente es difícil dar una noción exacta del servicio público en la actualidad porqué ni toda la actividad de la Administración es servicio público ni todo servicio público está en uun determinado momento en manos de ésta". (GarciaTrevijano Fos., J. A. Tratado de Derecho Administrativo, Madrid, Tomo II, Vol. L, p. 25.) 
sus tarifas. Es decir, la tendencia generalizada en las cilas de la nota anterior es recogida en nuestro ordenamiento jurídico al nivel más alto de las normas: la Constitución, cuando estableció expresa y claramente que en el caso de un servicio público prestado por empresas privadas, queda sometido a las regulaciones, vigilancia y aprobación de tarifas por el Estado y, en el caso de incumplimiento por esas empresas de los elementos básicos y necesarios de un servicio público, estaríamos en el caso de que los intereses sociales exigen que el Estado tome a su cargo la prestación del servicio (Art. 110, inciso 4o).

\section{Resumen}

En las páginas siguientes tratamos de presentar en forma resumida nuestros planteamientos antcriores. Al escribir nuestros trabajos estamos conscientes, y es necesario decirlo, que no creemos que podamos influir en decisiones ya tomadas lejos de aquí, aun cuando son obviamente contrarias a nuestro ordenamiento jurídico fundamental y pareciera que muy poco puede hacerse. Estamos viendo, para citar un solo caso, los resultados de la baja acelerada de los gravámenes a la importación que explican nuestro problema del balance comercial deficitario y las serias dificultades $y$ problemas de los pe- pretender a estas alturas que el cumplimiento de elementos esenciales de un servicio público no es responsabilidad del Estado significaría retroceder un siglo de dicho ordenamiento, lo cual realmente cuesta creer, al menos en el caso de los nacionales que han participado en la formulación de los documentos mencionados. Porque es dificil creer: (1) que no se hayan dado cuenta que el modelo económico salvadoreño cambió desde la Constitución de 1950, y (2) que la reforma de 1994 al Art. 110 por sus limitados alcances no pudo afectar el modelo intervencionista establecido por el constituyente de 1950 y mantenido por el de 1962, el de 1983 y que, en consecuencia, no fue modificado en lo esencial por las recientes reformas al Art. 110, inciso 4o constitucional.

Resulta, entonces, que si interpretamos nuestra Constitución en ese marco, y es necesario hacerlo así para formular la legislación secundaria que regule y desarrolle los principios constitucionales, el texto del Art. 16 del anteproyecto que comentamos, no tiene sentido por ser contraria esa formulación a nuestra Constitución. Aun cuando no tenemos ninguna duda sobre nuestro planteamiento al nivel constitucional determinado por su clara orientación que fácilmente se percibe cuando fue explícito y claro al concretar los valores, principios y objetivos de nuestra Carta Magna desde 1950. Y precisamente por eso, si se opta por el regreso al neoliberalismo, es que hemos queños y medianos empresarios que no pueden, ni podrán por mucho tiempo, competir con los productos extranjeros, cuando una disminución progresiva hubiera sido lo más apropiado y sensato. Sólo nos queda preguntarnos: ¿a nadie se le ocurrió?, o bien, ¿no se tomó en cuenta algún planteamiento en ese sentido si se hizo? Por eso tenemos el convencimiento de que mientras no cambie la dirección del viento (que probablemente no tardará en ocurrir) muy poco puede lograrse.

Los documentos de referencia en la preparación del presente trabajo (la $E$ de $M$ que comentamos en otro que citamos y el Art. 16 transcrito), concretan puntos de vista en los que se ignoran totalmente aspectos fundamentales de nuestro ordenamiento constitucional. Con mucha benevolencia hemos querido explicar esos interesados planteamientos como atribuibles al desconocimiento señalado la necesidad de reformar la constitución para estar en un Estado de Derecho; pero, no obstante lo anterior, hemos tratado de buscar otra explicación a los puntos de vista de los documentos y para eso hemos tratado de caracterizar la noción de "servicio público", a fin de identificar claramente cuáles son los elementos esenciales que tipifican ese concepto, pues ahí pudiera estar lo que explique la diferencia de criterios.

El análisis que hicimos de los puntos de vista de tratadistas respetables del Derecho Administrativo nos ayudaron a definir dos aspectos del servicio público que nos interesaban particularmente en el contexto de los problemas estudiados en este trabajo por los puntos de vista sustentados en ambos documentos. Nos referimos a la cuestión crucial de que un servicio público, aun cuando sea prestado por una empresa privada, no puede cambiar su 
naturaleza de lo que se entiende generalmente por servicio público, lo cual justifica la necesidad de una autorización del Estado por medio de la concesión que establece entre las obligaciones de quien presta el servicio, que éste debe cumplir los requisitos de continuidad, generalidad, igualdad, etc.

Particularmente centramos nuestra atención en tres características que son tal vez más importantes que las otras: (1) el derecho del usuario a tener acceso al servicio; (2) el régimen de Derecho Público que regula la concesión y la prestación del servicio, y (3) la determinación de la retribución que debe pagar el usuario por el servicio que siempre debe corresponder hacerla al Estado.

Entonces, las ideas centrales de la $E$ de $M$ y el Art. 16 del anteproyecto ignoran totalmente esos aspectos que son de general aceptación en la doctrina desde hace muchos años y que todavía prevalecen, cuando se pretende en los dos documentos de referencia, que debe haber necesariamente una libre contratación en la que obviamente el usuario, en notoria desventaja, no tendrá más alternativa que aceptar un contrato de adhesión en que todas las condiciones las fijará quien presta la concesión, pues su alternativa es quedarse sin el servicio que en muchos casos es necesario, esencial y de interés general.

Por eso señalamos que los autores de esos adefesios parecen haberse quedado detenidos en el tiempo, es decir, están desfasados cuando piensan que sólo es servicio público el prestado por el Estado, instituciones o empresas públicas $y$, en consecuencia, cuando lo presta una empresa privada prevalece la libertad de empresa como ellos la entienden, ignorando así ouros derechos consagrados en la Constitución como es el caso, sólo para citar un ejemplo del interés de los consumidores (Art. 101) y lo que es más grave contradiciendo la propia letra del inciso 4o del Art. 110 que se refiere expresamente a "servicios públicos prestados por empresas privadas".

En vista de lo anterior, la pregunta es ¿por qué no suprimieron esa parte cuando reformaron el Art. 110 en 1991 y 1994?; sería que los que redactaron la reforma conocían el significado de la noción de servicio público, o temieron las reacciones contrarias que podían dificultar la aprobación. Cualquiera que sea la explicación, el problema ahora se resuelve fácilmente como en muchos casos, simplemente ignorando el texto de la Constitución para resolver cualquier problema, lo que puede muy bien ser necesario, conveniente, etc. pero, eso no se puede hacer en un Estado de Derecho, y para evitarlo Kelsen instituyó la inconstitucionalidad, cuya declaración es una decisión que no es política sino jurídica y esa es la explicación del porqué no asignó esa responsabilidad al Presidente del Reich, como pretendía Schmill en La defensa de la Constitución y que Kelsen rebatió en un trabajo de 1931, publicado en castellano hasta el año pasado: Quién debe ser el defensor de la Constitución (Tecnos: Madrid, 1995).

No podíamos, dentro de los límites de este trabajo, extendernos más sobre las cuestiones estudiadas, pues simplemente hemos querido señalar algunos conceptos fundamentales que caracterizan el sentido propio de un servicio público, para estudiar con mayor detenimiento esa cuestión fundamental que dispone el Art. 246 constitucional: "Los principios, derechos y obligaciones establecidos por esta Constitución no pueden ser alterados por las leyes que regulen su ejercicio". Dando cumplimiento además al inciso 20 del mismo Art. 246 que manda: "La Constitución prevalecerá sobre todas las leyes y reglamentos" y, además conforme al mismo precepto: "El interés público tiene primacía sobre el interés privado".

Es por esas disposiciones de nuestra Constitución y muchas otras que concretan sus valores, principios y objetivos que nosotros compartimos los términos de la definición de servicio público del Profesor Escola cuando dice: "es aquella actividad de prestación que es asumida por la administración pública, en forma directa o indirecta, a fin de atender a la satisfacción de necesidades de interés público, bajo un régimen especial, predominantemente de derecho público"27.

27. Escola, Héctor Jorge. El interés público, cit., p. 118. De igual modo, otra definición que concreta el sentido propio actual de servicio público es la siguiente: "es toda actividad cuyo cumplimiento debe ser regulado, asegurado y fiscalizado por los lgobernantes, por ser indispensable a la realización y desenvolvimiento de la interdependencia social; y de tal es la naturaleza, que no puede ser asegurado completamente más que por la intervención de la fuerza gobemante". Agregando el autor a continuación: Es decir, se presupone en los 
Si compartimos los conceptos de la definición anterior es porque estamos conscientes que "Es un dato incuestionable que el Derecho Administrativo, surgido en el contexto de la Revolución liberal, ha ido construyendo fatigosamente sus técnicas con la atención puesta en la defensa de la libertad y de la propiedad del individuo frente a las eventuales injerencias no justificadas del poder público". Ese esquema, señalan los mismos tratadistas españoles, "satisfactorio, en principio, en el contexto social en el que inicialmente surgió y progresivamente se fue formando, ha dejado de serlo, sin embargo en la actualidad, dada la radical transformación de los supuestos sociales en que se apoyaba"2x.

Ese cambio y evolución transforma totalmente las responsabilidades del Estado hasta llegar hace unos cincuenta años a reconocer "el derecho de los administrados a obtener prestaciones de los servicios públicos (que es precisamente como se titula en la obra citada en la nota anterior la Sección $\mathrm{V}$ del Capítulo XVI). Y de ahí se configura un derecho a la creación y mantenimiento de los servicios públicos y de igual modo se deriva el derecho al uso y disfrute de los servicios existentes que se acepta generalmente en la actualidad y que fue precisamente lo que recogió el constituyente de 1950 y concretó en múltiples disposiciones. En tal situación, ¿cómo es posible que sigamos pensando en el concepto primigenio de servicio público? Sólo se explica para los que están desfasados, o sea, fuera de época con unos cien años de retraso o para quienes quieren vender el país como se ha dicho en un reciente seminario en el lugar de donde vienen las órdenes.

Para terminar, deseamos dejar a la consideración de quienes hacen las decisiones unas últimas reflexiones. El problema de la reforma de 1994 es que el urgente y obligado afán privatizador llevó a modificar la obligación del Estado de prestar los servicios de correos y telecomunicaciones, de este modo ignoró a la propia naturaleza del servicio público, aun cuando los autores se vieron obligados a reconocer en el texto de la reforma que "cuando los intereses sociales así lo exijan" el Estado "podrá" tomar esos servicios y cualquiera otros a su cargo. El verbo correcto que debió emplearse es "deberá" porque es de la propia obligación y responsabilidad del Estado prestar esos servicios directamente porque los intereses sociales así lo exigen.

Si un servicio público concedido a particulares se presta en forma indebida, no sólo el concesionario es responsable, sino también la administración pública que tiene todos los medios y posibilidades jurídicas para que el servicio sea prestado en la forma debida y apropiada. Eso se dispuso aun en la reforma de 1994.

Parte importante de la forma apropiada de prestar el servicio es como lo dijo el Maestro Bielsa, hace muchos años, que la tarifa debe ser "justa y razonable". Lo que también está previsto en el Art. 110 , inciso 40 , cuando se ordena la aprobación de las tarifas por el Estado, las que obviamente con toda seguridad no pueden ser las que pretendan los buitres de las transnacionales, que "arreglan" los zorros nacionales y aceptan los otros a que se refiere la cita que hicimos antes, cuando nos referimos a ese sainete ridículo engaña bobos.

De todo lo que hemos reseñado resulta la ofensiva contra el Estado cuando presta directamente los servicios públicos, que ha descansado equivocadamente o más bien malintencionada e interesadamente, en un criterio de rentabilidad o más de lucro, que no debería emplearse, como cuando se trata de actividades privadas regidas por el mercado, pues en este caso consiste en el beneficio empresarial. Como alguien dijo, es una rentabilidad contra los usuarios; es decir, contra los débiles, lo que es menos justificado cuando se privatizan las actividades más rentables. Finalmente, debe quedar claro que es inaceptable creer que la

gobernantes una obligación efectiva de satisfacer las necesidades cada vez más crecientes de la también cada vez más compleja sociedad actual". (Serrano Triana, Adolfo. La utilidad de la noción de servicio público y la crisis del Estado bienestar, cit., p. 37).

28. García de Enterria, Eduardo y Fernández, Tomás-Ramón. Curso sobre Derecho Administrativo, Madrid, 1986, Tomo II, p. 66. Pero los distinguidos administrativos españoles precisan que si "la función del Derecho Publico ya no se agota en la pura defensa de la libertad y de la propiedad individuales, a la cual estaba inicialmente orientado de forma casi exclusiva, aunque esta función siga siendo imprescindible (los derechos fundamentales no han pasado a la historia, como con notorio exceso y en un ambiente especialmente proclive a este tipo de afirmaciones dijera Forsthoff en la Alemania de 1938...)" (op cit., p. 67). 
rentabilidad económica pueda ser un criterio sustitutivo del interés general. En modo alguno podrian ser siquiera equivalentes, ni por su finalidad ni por su origen.

J. Kenneth Galbraith calificó como "seriamente cuestionable" la creencia "de que la libertad se mide, como es habitual en Nueva York, por la cantidad de basura sin recoger. Esa penetrante ironía de Galbraith ha sido comentada como "una verdadera respuesta al absurdo dilema en que nos intentan situar los meros abanderados de la libertad, pues habríamos de aceptar para tenerla por coherente, que la existencia de obligaciones constitucionales para que el Estado intervenga en la vida de la colectividad prestando servicios públicos, es esencialmente incompatible con la prosperidad económica, la libertad de los grupos sociales y el sano latido de una sociedad occidental"29.

Estamos comenzando a ver una profunda insatisfacción respecto a los logros milagrosos de los ajustes "naturales" del mercado. $Y$ aun cuando fuera el último, por mi formación, en negar la importancia del análisis económico, no he creído nunca en esa fe que aparentan tener algunos en la economía como una disciplina de soluciones unívocas y exactas. Por otra parte, no puedo aceptar que problemas sociales primordialmente deban resolverse con un exclusivo enfoque económico. Por eso compartimos el criterio de quienes piensan que la economía de un país se debe ajustar a las necesidades sociales y no al contrario, por lo que corresponde al Estado instrumentar a la economía para beneficio de la generalidad. Los economistas deben simplemente dar las soluciones técnicas a las decisiones políticas previas adoptadas en el marco jurídico de un Estado democrático. Ya lo dije en otro trabajo que una vez conversamos con mi desaparecido amigo el Profesor Cesare Cosciani de la Universidad de Roma, y coincidimos que el asesor económico únicamente debe señalar las consecuencias de las medidas que adopten a quienes corresponde tomar las decisiones.

Además, y no por eso menos importante, no es del todo inútil una presencia distinta porque es discordante, al menos por algo que recordábamos en un trabajo nuestro refiriéndonos a esa actitud reflejada en el silencio generalizado frente a lo que está ocurriendo, que Julián Marías llamaba "pesimismo pasivo", que concreta algo preocupante cuando una buena parte de la sociedad no se atreve a manifestar lo que piensa. $Y$ es que pareciera haberse olvidado algo que es obvio, como decía D. Luis María Diez-Picazo, el distinguido Profesor de Derecho Público ibero, "cualquier ley debe respetar, so pena de invalidez, los dictados constitucionales".

Graham Greene, gran novelista inglés, se refirió a Charles Peguy así: "Ningún otro escritor ha vivido el cristianismo como lo vivió Peguy", a quien recordamos al escribir este trabajo pues Peguy creía que se debe "Decir la verdad, toda la verdad, nada más que la verdad, decir brutalmente la verdad brutal, molestamente la verdad molesta, tristemente la verdad triste", pues, como bien dijo Don Antonio Machado: "la verdad es lo que es y sigue siendo la verdad".

29. Serrano Triana, Adolfo. La utilidad social de la noción de servicio público, cit., p. 13. 